\title{
Natura@economía
}

ISSN 2226-9479 (Versión electrónica)

Website: http://revistas.lamolina.edu.pe/index.php/neu

\section{Estudio económico del residuo quesero en la producción de nata, concentrado proteico y bioetanol}

\author{
Economic study of the cheese residue in the production of cream, protein concentrate \\ and bioethanol
}

\author{
Jose Antonio Flores Bao ${ }^{1 *}$; Sarita Llerena Francia²; Alejandrina Sotelo Mendez ${ }^{1}$; \\ Davys Berrospi Sanchez ${ }^{1}$
}

${ }^{1}$ Universidad Nacional Agraria La Molina, Av. La Molina s/n, Lima, Perú. Email: jflores@lamolina.edu.pe;
asotelo@lamolina.edu.pe; dberrospi@lamolina.edu.pe
${ }^{2}$ Compañía de Minas Buenaventura SAA, C/ Las Begonias 415, Lima, Perú. Email: sarita.1lerena@buenaventura.pe

Recepción: 26/09/2019; Aceptación: 15/12/2019

\begin{abstract}
Resumen
El objetivo que se persigue es el de estudiar la viabilidad económica de un proceso de recuperación de productos a partir del suero lácteo generado en queserías artesanales de la sierra del Perú, se pretende revalorizar un hasta ahora considerado residuo industrial mediante su transformación en subproductos alternativos. Se utilizó herramientas de análisis financieros que permitieron identificar y analizar las relaciones y factores financieros, con la finalidad de obtener el análisis económico financiero a partir de los estados contables de industrias lácteas en el Perú. La evaluación económica realizada muestra resultados aparentemente favorables, conllevando ahorro en materias primas en la sustitución de fuentes de proteína como la soja o la leche y beneficios ambientales relacionados con la reducción de emisiones de gases de efecto invernadero y la contaminación de suelos y aguas.
\end{abstract}

Palabras clave: balance económico; costos fijos; costos de producción; análisis de inversiones.

\begin{abstract}
The objective pursued is to study the economic viability of a product recovery process from the whey generated in artisanal cheese factories in the highlands of Peru, it is intended to revalue a hitherto considered industrial waste through its transformation into alternative byproducts. Financial analysis tools were used to identify and analyse the financial relationships and factors, in order to obtain the financial economic analysis from the financial statements of dairy industries in Peru. The economic evaluation shows apparently favourable results, leading to savings in raw materials in the substitution of protein sources such as soy or milk and environmental benefits related to the reduction of greenhouse gas emissions and the contamination of soils and water.
\end{abstract}

Keywords: economic balance; fixed costs; production costs; investment analysis.

Forma de citar el artículo: Flores et al., 2019. Estudio económico del residuo quesero en la producción de nata, concentrado proteico y bioetanol. Natura@economía 4(2): 94-104 (2019).

* Autor de correspondencia: Jose Antonio Flores Bao. Email:jflores@1amolina.edu.pe;

(C) Facultad de Economía y Planificación, Universidad Nacional Agraria La Molina, Lima, Perú. 


\section{Introducción}

El suero lácteo es el líquido residual obtenido tras la precipitación de la caseína de la leche en los procesos de producción de queso (Onwulata y Huth, 2008). Este subproducto representa sobre un $85-95 \%$ del volumen de materia prima utilizado en la producción del queso y retiene un 55\% de los nutrientes de la leche (Siso, 1996). Además, es un importante problema medioambiental debido a la alta proporción de lactosa que contiene (un $65 \%$ del peso de los sólidos) y, principalmente, a las altas cantidades que se producen en el mundo (Walstra et al., 2006). La producción mundial del lactosuero supera los 160 millones toneladas por año (estimado como 9 veces la producción de queso), mostrando una tasa de crecimiento anual de 1 a 2\% (Guimarães et al., 2010). Teniendo en cuenta que hasta un $85-90 \%$ de esta leche utilizada para la producción de queso se va a desechar como suero lácteo, se estiman en unas 2800000 t/año la producción de dicho subproducto (Jelen, 2011). Debido a su gran capacidad contaminante, con una DBO comprendida entre 30000 y $50000 \mathrm{mg} / \mathrm{L}$, y al valor nutritivo de los componentes del suero de la leche, se han dirigido en todo el mundo considerables esfuerzos dedicados su aprovechamiento (Maiorella, y Castillo, 1984). Se considera que tan sólo el vertido diario de unos $60 \mathrm{~m}^{3}$ al día, producen la misma contaminación que una ciudad de unos 30000 habitantes (Prazeres et al., 2012). Tanto los propios gobiernos como los centros privados han impulsado el desarrollo de procesos de aprovechamiento del suero lácteo para evitar su vertido a las corrientes acuíferas naturales. La sierra del Perú es una comunidad con una amplia tradición quesera, esto supone una amplia riqueza en cuanto a tipos de quesos distintos, supone también un gran inconveniente a la hora de tratar el suero lácteo producido por las queserías artesanales, el total de litros de suero lácteo producido en la sierra del Perú por las queserías de tipo tradicional asciende a unos 15 millones de litros, lo que supone actualmente un importante problema de gestión (MINAGRI, 2018). Esto supone la necesidad de un exhaustivo conocimiento de la industria láctea en la región con el objetivo de proponer una solución integral al exceso de suero generado en estas industrias. Rosenberger et al. (2001) argumentan que una de esas alternativas la representan los biocombustibles (bioetanol y biodiesel), productos obtenidos sobre todo a partir de los cereales o plantas oleaginosas, que en un principio supuso una gran ventaja, se está convirtiendo en el principal problema de la producción de biocombustibles a raíz de ese aumento de la demanda para uso energético, sin que crezca de forma notable la oferta de los cultivos. En menos de dos años se han encarecido los precios de los piensos del ganado en una media del $25 \%$ y países como Mexico, cuya alimentación está basada en el consumo de maíz, han pasado por graves crisis alimenticias debido a su relativa escasez y carestía, parece ser entonces que el futuro de los biocombustibles pasa por encontrar una alternativa a las cosechas dedicadas a fines energéticos y esta alternativa podría ser el uso de residuos con alto contenido en biomasa, como por ejemplo el suero lácteo (Tan et al., 2008). Cabe destacar que existen ya dos iniciativas bioenergéticas en el sector lácteo dentro del panorama internacional. En Europa la más relevante es la de la empresa alemana Müllermilch, que cuenta con una central láctea de Leppersdorf una fábrica de bioetanol y que utilizan como materia prima el suero lácteo que producen como residuo en la fabricación de queso (Kühl et al., 2016). Por otro lado, en EEUU, la planta de la empresa John Koller and Son Inc, en Pensilvania, utiliza una sofisticada tecnología, a partir de un digestor anaeróbico, para obtener biogás a partir de la transformación del suero lácteo (Greer, 2008).

Por lo expuesto, el objetivo del estudio fue obtener el mayor aprovechamiento posible del suero lácteo; para ello, se llevó a cabo dos separaciones previas a la obtención del bioetanol que tuvo como resultado la producción de un concentrado graso y de un concentrado proteico, ambos productos con un gran potencial de comercialización y contribuyo de forma considerable a un mayor margen de beneficios.

\section{Materiales y métodos Costos fijos o Capital Inmovilizado}

Dentro del capital inmovilizado se incluyó el equipamiento básico de la planta (costos de equipos e instalación). Para el cálculo del costo inmovilizado se utilizó los factores del método de Chilton (Tabla 1). Para ello se partió de la suma de costos de los equipos principales del proceso. 
Tabla 1: Factores del método de Chilton

\begin{tabular}{lc}
\hline Costos Directos & Factores de costo \\
\hline Equipos & 1 \\
Instrumentación & $0,10^{*} \mathrm{C}$ equipo \\
Impuestos de ventas & $0,03 * \mathrm{C}_{\text {Cequipos }}$ \\
Transporte & $0,05^{*} \mathrm{C}_{\text {equipos }}$ \\
\hline Costos Directos de la instalación & Factores de costo \\
\hline Cimentación & $0,12^{*} \mathrm{C}_{\text {directos }}$ \\
Obra civil & $0,4^{*} \mathrm{C}_{\text {diriectos }}$ \\
Electricidad & $0,01 * \mathrm{C}_{\text {directos }}$ \\
Red de tuberías & $0,3 * \mathrm{C}_{\text {directos }}$ \\
Aislante & $0,01 * \mathrm{C}_{\text {directos }}$ \\
Pintura & $0,01 * \mathrm{C}_{\text {directos }}$ \\
\hline
\end{tabular}

Costos Indirectos de la instalación $\quad$ Factores de costo

Gastos de Construcción

Honorarios del contratista

Puesta en marcha

Pruebas de funcionamiento

Contingencia

$0,10 * C_{\text {directos }}$
$0,10^{*} C_{\text {directos }}$
$0,10^{*} C_{\text {directos }}$
$0,01 * C_{\text {directos }}$
$0,01 * C_{\text {directos }}$
$0,03 * C_{\text {directos }}$

Factores de costo

Costos directos totales tangibles 1,0

Costos directos totales intangibles $\quad 0,1$

Imprevistos

0,1
Ingeniería

0,10. Mientras que, para la ingeniería y construcción, al tratarse de una planta de complejidad simple, la suma total de esta partida fue del $20 \%$ del capital físico.

\section{Costos variables}

Las materias primas, el costo es nulo, ya que la empresa estaría controlada por las diferentes asociaciones de queseros artesanales de la sierra, proveedores del suero lácteo. Los materias auxiliares, se tuvo en cuenta el costo de las levaduras que llevarán a cabo la fermentación del suero lácteo. Se trató de reutilizar los microorganismos en cuatro ciclos de fermentación, lo que reducirá de forma considerable el costo de esta partida. El costo por los servicios, dependió

\section{Costos de equipos}

$\mathrm{Su}$ valor será estimado a partir de diferentes fuentes bibliográficas (Peters et al., 1968). Para su actualización se utilizó el índice de la revista Chemical Engineering. Para el costo de equipos instalados, se tomó un factor de 1,5 en el método de Chilton. El costo de tuberías, válvulas y transporte, se determinó en plantas donde se procesan líquidos y sólidos, se estimó que esta partida tendrá un valor de $15 \%$ del costo de los equipos sin instalar. Los instrumentación de medición y control, en un grado de automatización medio, el costo de la instrumentación instalada en la planta se estimó al 5\% del costo de los equipos instalados.

El terreno y edificios, la planta se instaló en la sierra del Perú y con unas necesidades de $2000 \mathrm{~m}^{2}$, tomando como referencia una planta mixta, el costo de la edificación fue del $20 \%$ del costo de los equipos instalados.

Auxiliares: potencia, vapor y agua, entre otros, para este rubro se consideró un factor de 0,10 . En relación a la contingencia y beneficio del contratista, se aplicó en el cálculo para esta partida un factor de fundamentalmente de los gastos de agua, gas y electricidad de la planta, además de otros de menor valor.

\section{Costos fijos}

El mantenimiento, se estimó como el 5\% del capital fijo. La mano de obra directa, tiene suficiente grado de automatización, fueron tres operarios y un director de planta. Los seguros, se estiman como el $1 \%$ del capital fijo. Los impuestos, se pagaron según los impuestos locales, cuya cantidad se estima en el $2 \%$ del capital fijo.

\section{Análisis de inversiones}

Valor actualizado neto (VAN), mide la deseabilidad de un proyecto en términos absolutos. Calcula la cantidad total en que ha aumentado el capital como consecuencia del proyecto. Dadas unas cantidades $\mathrm{Ct}$ y una tasa de descuento $r$, el VAN de un proyecto que se ejecuta en el momento $\mathrm{M}$ se mide mediante la función: $\operatorname{VAN}\left(\mathrm{C}_{\mathrm{t}}, \mathrm{r}\right)=\mathrm{C}_{\mathrm{M}} /$ $(1+\mathrm{r})^{\mathrm{M}}+\mathrm{C}_{\mathrm{M}+1} /(1+\mathrm{r})^{\mathrm{M}+1}+\ldots+\mathrm{C}_{\mathrm{M}+\mathrm{T}} /(1+\mathrm{r})^{\mathrm{M}+\mathrm{t}}$. Siendo $\mathrm{r} \neq-1$ y $\mathrm{t}=0,1, \ldots, \mathrm{M}+\mathrm{T}$. 
Tasa interna de rentabilidad (TIR), expresa el crecimiento del capital en términos relativos y determina la tasa de crecimiento del capital por período. Las TIR se definen como toda $\mathrm{r}^{*}{ }_{\mathrm{j}}$ tal que $\operatorname{VAN}\left(\mathrm{C}_{\mathrm{t}}\right.$, $\left.\mathrm{r}_{\mathrm{j}}^{*}\right)=0$

\section{Resultados y discusión}

\section{Bases de diseño}

\section{Alimentación}

Según el plan de recogida del suero lácteo, se han estimado los siguientes caudales máximos y mínimos a almacenar diariamente: se realice con el suero lácteo una vez haya llegado a la planta. Para ello, y como es habitual en la industria láctea, se utilizará una centrífuga de discos con la que se puede obtener un concentrado de materia grasa comprendido entre el 35-40\%. Éste puede ser comercializado como nata, para lo que necesita ser envasado y refrigerado, dejando unos importantes ingresos por ventas.

Tras este primer paso y siguiendo con las operaciones que se realizan comúnmente en toda industria láctea, se llevará a cabo un tratamiento térmico del suero lácteo desnatado a fin de conseguir una estabilidad microbiológica adecuada.

Tabla 2: Caudal de suero almacenado diariamente

\begin{tabular}{cccc}
\hline \multicolumn{2}{c}{ Máxima producción } & \multicolumn{2}{c}{ Mínima producción } \\
\hline Lunes, miércoles y viernes & $60000 \mathrm{~L} / \mathrm{d}$ & Lunes, miércoles y viernes & $31310 \mathrm{~L} / \mathrm{d}$ \\
Martes, jueves y sábados & $59200 \mathrm{~L} / \mathrm{d}$ & Martes, jueves y sábados & $40070 \mathrm{~L} / \mathrm{d}$ \\
\hline
\end{tabular}

Tabla 3: Composición media del suero lácteo acido en la sierra del Perú

\begin{tabular}{cc}
\hline Componente & $\begin{array}{c}\text { Concentración } \\
(\% \text { peso })\end{array}$ \\
Lactosa & 4,50 \\
Proteínas & 0,92 \\
Materia grasa & 0,65 \\
Minerales & 0,60 \\
\hline
\end{tabular}

Según los resultados reportados por García et al. (1991) fueron materia grasa 0,3$0,6 \%$, proteínas $0,8-1,0 \%$, minerales $0,7-0,8$ y lactosa 3,8-4,2 en la sierra de Cantabria (España), resultados similares, pero con una pequeña diferencia con la lactosa, minerales y materia grasa.

A la vista de los resultados anteriores las bases de diseño fueron: Caudal máximo: $60000 \mathrm{~L} / \mathrm{d}$; Concentración de proteínas: $10 \mathrm{~g} / \mathrm{L}$; Concentración de lactosa: $50 \mathrm{~g} / \mathrm{L}$; Concentración de materia grasa: $10 \mathrm{~g} / \mathrm{L}$ y Extracto seco total: $6,5 \%$.

\section{Justificación de operaciones}

Debido a que la materia grasa supone un gran inconveniente a la hora de trabajar con equipos de membranas, la separación previa de la misma será la primera operación que
Para ello será suficiente con una etapa de pasterización, pues el tiempo que va a permanecer almacenado dicho suero antes de ser finalmente procesado no va a requerir procesos más contundentes. Se realizaron una serie de etapas enfocadas a la obtención del concentrado proteico que, a la postre, será el que mayores ingresos proporcione. Para ello, siguiendo procesos ya establecidos a nivel industrial, se llevará a cabo una etapa de ultrafiltración discontinua en la que se obtendrá un retenido rico en proteínas que finalmente dará lugar a un concentrado proteico de hasta el $65 \%$ en peso, previo secado por aspersión. Los concentrados proteicos están tomando cada vez más importancia en el mercado debido a que cuentan con un número creciente de aplicaciones, la mayor parte de ellas alimentarias. Estos, tras una serie de acondicionamientos posteriores, son comúnmente utilizados en dietas especiales como las dietas para deportistas, alcanzando unos precios en el mercado que pueden llegar hasta los 100 soles $/ \mathrm{kg}$. También se utilizan como aditivos en gran cantidad de productos de charcutería por sus características aglutinantes, de extensión y modificación de textura, e incluso para producción de films comestibles.

Para que los gastos en la etapa de 
destilación posterior a la producción de bioetanol no sean excesivamente altos, se optó por la concentración del permeado de ultrafiltración hasta alcanzar unos niveles de lactosa cercanos a $150 \mathrm{~g} / \mathrm{L}$. Esta concentración se consigue fácilmente mediante una operación de ósmosis inversa. Además, de este proceso se obtiene también una corriente de agua que puede ser reutilizada en diferentes partes de la planta como agente refrigerante $y$ finalmente como agua de limpieza, disminuyendo notablemente los gastos de este bien.

La fermentación para producir el bioetanol se llevará a cabo en fermentadores cilindrocónicos por la acción de la levadura Kluyveromyces marxianus. No es necesario preparar un inóculo de levadura cada vez que se comience una fermentación ya que ésta va a ser reutilizada en un ciclo de cuatro fermentaciones sucesivas. Una vez que dicho ciclo se complete y, tras el previo secado de la levadura, podrá ser utilizada para alimentación animal.

Las levaduras del género Kluyveromices son los microorganismos escogidos en muchas plantas industriales para la producción de etanol a partir de suero lácteo. Así, en procesos de fermentación discontinua, $K$. fragilis utiliza más del $95 \%$ de la lactosa presente en suero lácteo no concentrado, con una eficiencia de producción de etanol del $80-85 \%$ sobre el teórico valor de $0,538 \mathrm{~kg}$ etanol $/ \mathrm{kg}$ lactosa consumida (Parrondo et al., 2000).

El etanol obtenido de esta manera debe ser deshidratado para poder utilizarse como combustible. Para ello, y debido a la existencia de un azeótropo en el equilibrio etanol-agua, no es suficiente con una etapa de rectificación. Deberá llevarse a cabo una operación de secado final que, en este caso, consistirá en un tamizado molecular. Según Pérez-Bermúdez y Garrido-Carralero (2011) argumenta que los sistemas de deshidratación de alcohol con tamices moleculares se han impuesto en la industria en los últimos años. Se demuestra que las variables de operación de mayor importancia para alcanzar el funcionamiento óptimo de un sistema de este tipo, son: la estabilidad del vapor, las diferencias de presión y temperatura en el empaque, el grado alcohólico del etanol hidratado, entre otras. Toda esta operación es visualizada en la Figura 1 y Figura 2.

Tabla 4: Cost.os de equipos

\section{Pretratamiento}

\section{Soles}

E-P01 (Desnatadora, 10000 L/h, 2500 rpm)

280000

E-P02 (Pasterizador suero, $10000 \mathrm{~L} / \mathrm{h}$ )

200000

E-P04(envasadora de nata)

28000

Concentrado proteico

E-CP01(ultrafiltración, discontinuo, $15000 \mathrm{~L} / \mathrm{h}$ )

800000

E-CP03 y accesorios (secadero spray, $14 \mathrm{ft}$ diámetro)

960000

E-EP03 (envasadora concentrado proteico)

60000

Ósmosis inversa

E-E01 (Ósmosis Inversa, 15000 L/h)

1200000

\section{Fermentación}

E-E02, E-E03, E-E04 (propagadores, encamisados, no agitados)

E-E05 (propagador $4000 \mathrm{~L}$, encamisado, no agitado)

E-E06, E-E07, E-E08 (75 000 L, encamisados, no agitados, ac inox)

1320000

E-E09 (Centrífuga de discos, 10000 L/h, 4000 rpm)

360000 


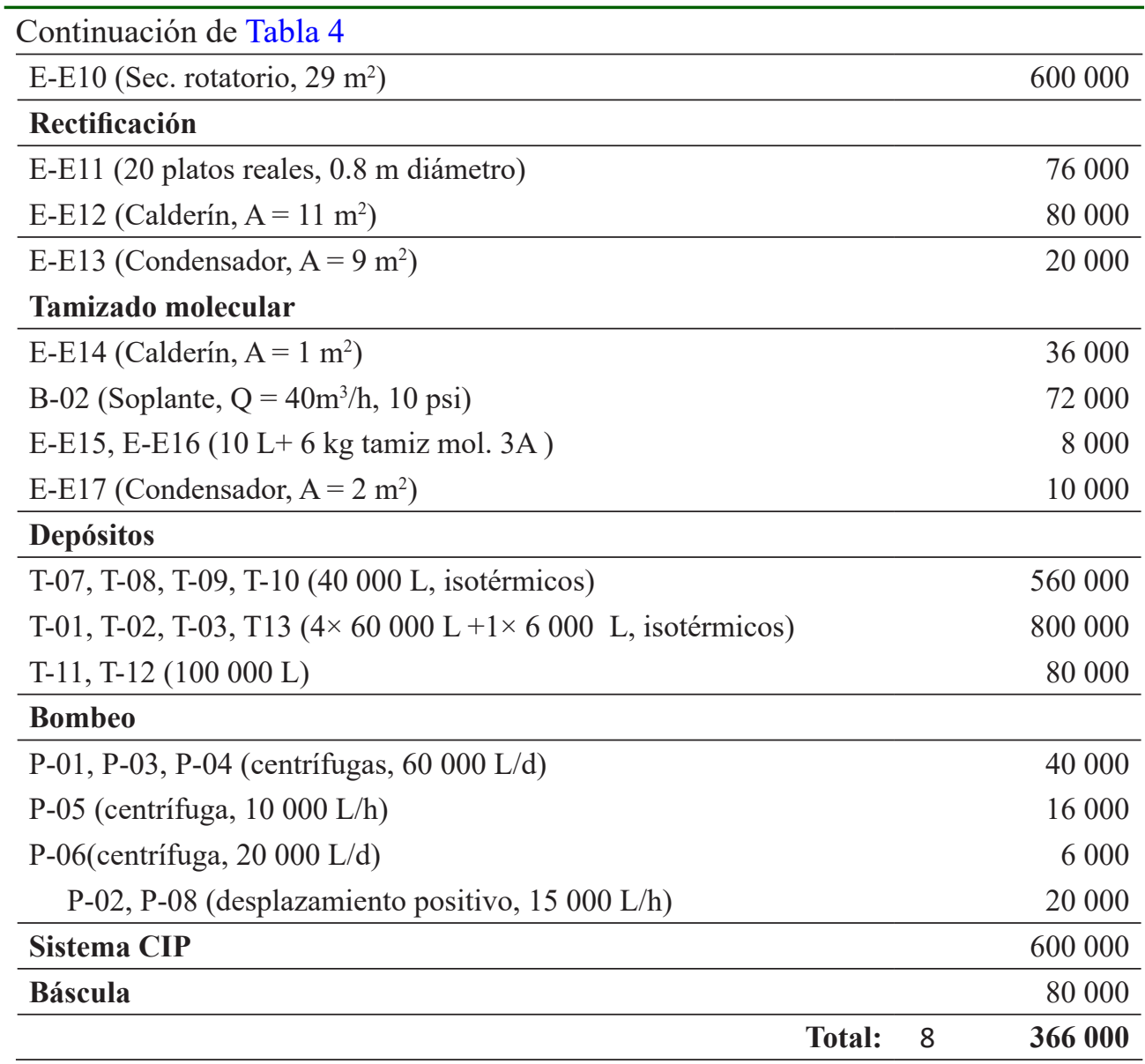

\section{Ingresos por ventas}

\section{Nata}

El precio actual en el mercado del kilogramo de grasa butirométrica es de S/ 10. Teniendo en cuenta la cantidad de nata producida a diario en la planta $(1714 \mathrm{~L} / \mathrm{d})$ y la concentración de materia grasa en la misma, al cabo del año reportará el siguiente ingreso: 2627564 soles / año.

\section{Concentrado proteico}

El precio de mercado de los concentrados proteicos depende mucho de la proporción de proteínas que contienen. Así, según datos del año 1996, un concentrado proteico con $33 \%$ de proteínas en base seca tenía un precio de 1,32 dólares $/ \mathrm{kg}$, mientras que un concentrado con $72 \%$ de proteínas en base seca tenía un precio de 4,52 dólares/ $\mathrm{kg}$ (Hsu y Kolbe, 1996). Partiendo de estos datos, actualizándolos y suponiendo una relación lineal entre el precio del producto y el porcentaje de proteínas que contiene, el concentrado proteico de $60 \%$ de proteína tendrá un precio de 13,6 soles $/ \mathrm{kg}$. Teniendo en cuenta la producción anual de este producto, los ingresos obtenidos por su venta serán de 4566880 soles/año.

\section{Bioetanol}

Para el bioetanol, según referencias del Osinergmin, su precio de venta está en torno a 3,2 soles/L. De la misma forma, conocida la producción diaria de 1920 L/d de este producto puede estimarse los ingresos que genera 1962240 soles/año 


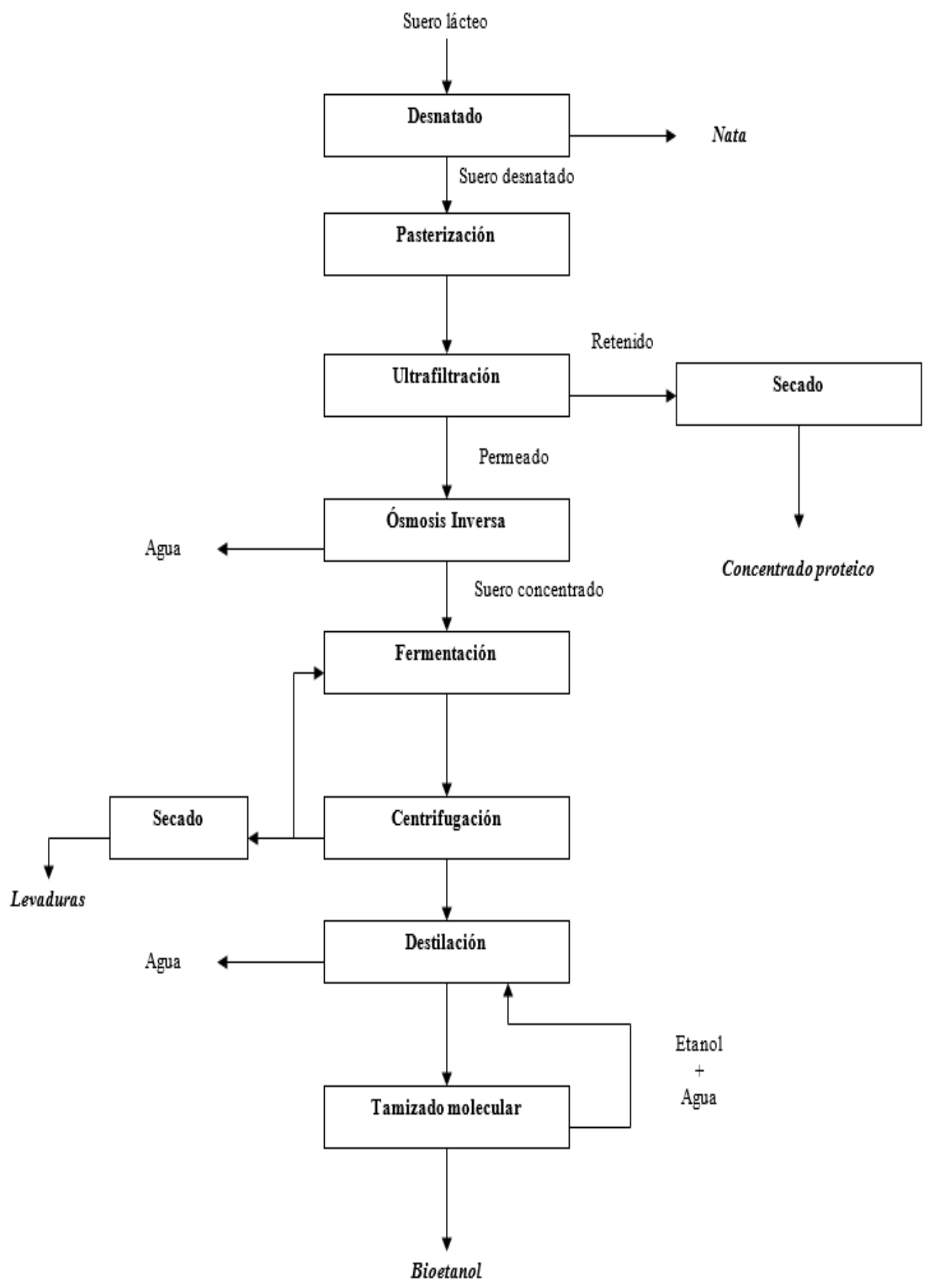

Figura 1: Diagrama de flujo 
Flores et al. / Natura@economía 4(2): 94-104 (2019)

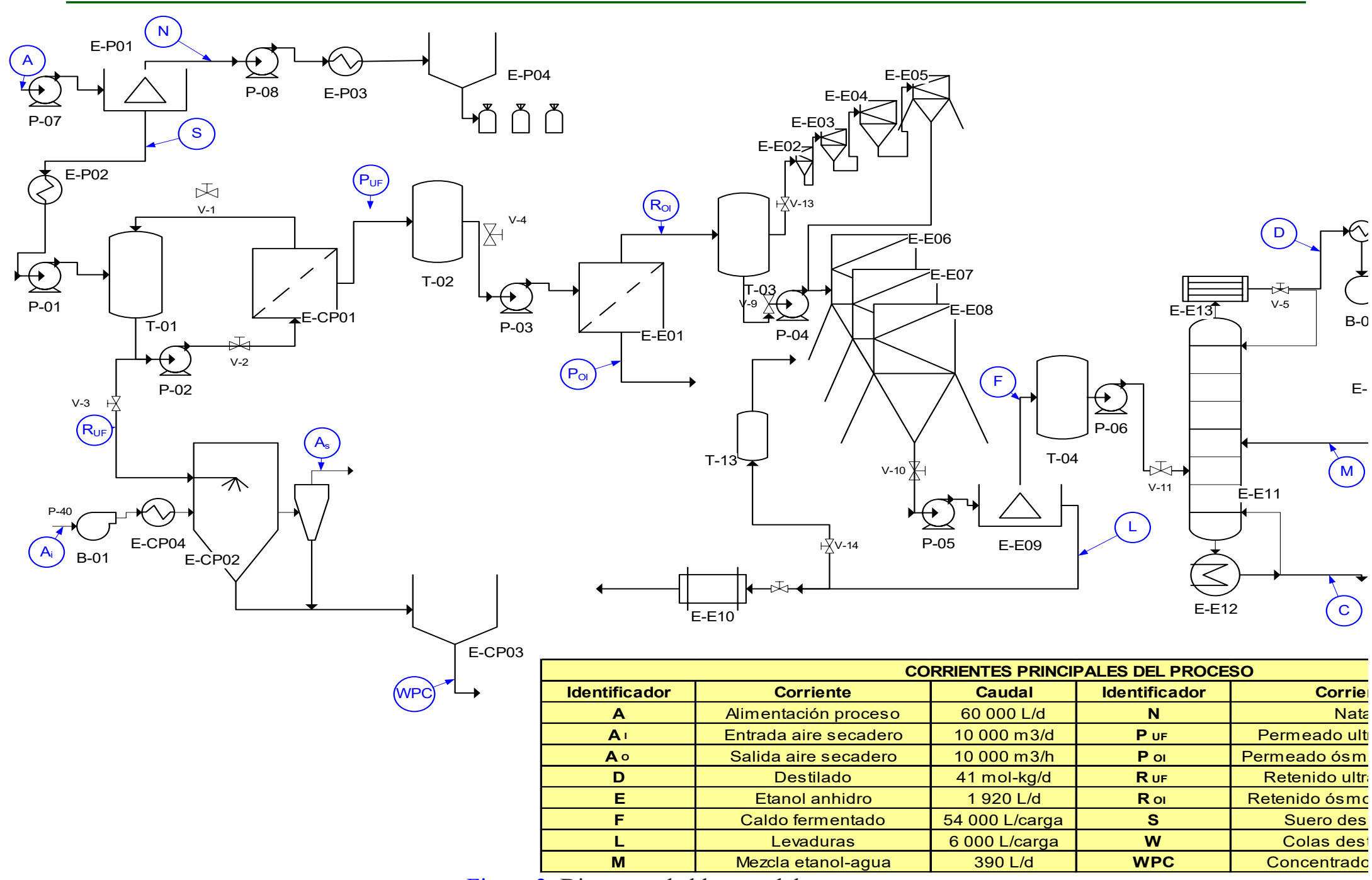

Figura 2: Diagrama de bloques del proceso 


\section{Proteína unicelular}

Ésta se venderá como suplementación para alimentación animal. Una vez revisado el precio actual de los piensos (1 sol $/ \mathrm{kg}$ ) se decide poner un precio a la misma de 0,40 sol $/ \mathrm{kg}$. La cantidad producida será de unos $900 \mathrm{~kg}$ de proteína unicelular por cada ciclo completo de fermentación. El ciclo de fermentación tiene una duración cercana a los 45 días, por lo que se llevarán a cabo 8 ciclos a lo largo del año. Así, los ingresos obtenidos por este concepto serán de 4320 soles/año.

Como se puede ver estos ingresos son despreciables frente al resto de ventas de la planta, pero la producción de la proteína unicelular supone la desaparición del problema de gestión de estos lodos, con su consiguiente costo. Los ingresos totales por ventas ascienden a 9161004 soles/año.

\section{Cuenta de resultados}

La cuenta de pérdidas y ganancias, también llamada de resultados, recoge información referente a la corriente de ingresos y gastos con el transcurso del ejercicio. Dentro de los gastos se consideraron: materias primas; gastos de personal; trabajos, suministros y servicios exteriores; amortizaciones: se tendrá en cuenta un tiempo de amortización de los equipos de 10 años e impuestos. En cuanto a los ingresos, se tendrá en cuenta: ventas o ingresos de explotación; subvenciones e ingresos financieros.

De acuerdo con los puntos citados anteriormente y con los cálculos llevados a cabo, se muestra a continuación la cuenta de resultados de la explotación en forma analítica:

\begin{tabular}{|c|c|}
\hline Ventas & +9161004 \\
\hline Subvención & $+\quad 862876$ \\
\hline Consumo materias primas & 696640 \\
\hline Mano de obra & 426400 \\
\hline Gastos generales & -2152524 \\
\hline Amortizaciones & 836600 \\
\hline BENEFICIO ANTES IMPUESTOS & $=5911712$ \\
\hline $\begin{array}{l}\text { Impuestos }(35 \%, \text { sin contar } \\
\text { etanol) }\end{array}$ & -1382316 \\
\hline BENEFICIO NETO = & 4529264 \\
\hline
\end{tabular}

Como se aprecia en la cuenta de resultados, los beneficios netos que podría obtener la empresa son considerables. Sin embargo, no se han tenido en cuenta para su cálculo los gastos financieros (pago de intereses de préstamos) que sin duda reducirían dicho beneficio.

\section{Tablas resumen}

Tabla 5: Capital inmovilizado

\begin{tabular}{lr}
\hline \multicolumn{2}{c}{ Capital inmovilizado } \\
\hline \multicolumn{1}{c}{ Partida } & \multicolumn{1}{c}{ Costo (S/) } \\
\hline Costo equipos & 8366000 \\
Costo equipos instalados & 12549000 \\
$\begin{array}{l}\text { Tuberías, válvulas y } \\
\text { transporte }\end{array}$ & 1882352 \\
$\begin{array}{l}\text { Instrumentación, medición } \\
\text { y control }\end{array}$ & 627452 \\
Terreno y edificios & 3229800 \\
Auxiliares & 1254900 \\
\hline \multicolumn{1}{c}{ Costo físico total: } & 19543500 \\
\hline $\begin{array}{l}\text { Ingeniería y construcción } \\
\text { Contingencias y beneficio } \\
\text { contratista }\end{array}$ & 3908700 \\
\hline
\end{tabular}

Total: 25406552

Tabla 6: Costos de producción

Costos de producción

\begin{tabular}{lr}
\hline \multicolumn{2}{c}{ Costos de producción } \\
\hline \multicolumn{1}{c}{ Partida } & \multicolumn{1}{c}{ Costo (S/) } \\
\hline Costos variables: & 688000 \\
\hline Materias primas & 8640 \\
Materias auxiliares & 120000 \\
Servicios & \\
\hline Costos fijos: & 1270328 \\
\hline Mantenimiento & 426400 \\
Mano de obra directa & 254064 \\
Seguros & 508132 \\
Impuestos locales & 3275564 \\
\hline \multicolumn{2}{c}{ Total: }
\end{tabular}


Tabla 7: Ingresos

\begin{tabular}{lr}
\hline \multicolumn{2}{c}{ Ingresos } \\
\hline \multicolumn{1}{c}{ Partida } & Costo $(\mathrm{S} /)$ \\
\hline Ventas: & 2627564 \\
Nata & 4566880 \\
Concentrado proteico & 1962240 \\
Bioetanol & 4320 \\
Proteína unicelular & 862876 \\
Subvención & 10023876 \\
\hline Total:
\end{tabular}

\section{Valor actualizado neto (VAN)}

Como horizonte temporal de inversión se tomará el tiempo de vida útil de la planta, que suele ser de 10 años. El periodo de construcción y puesta en funcionamiento de la planta durará aproximadamente un año. Según vaya transcurriendo dicho proceso, se irán programando los distintos pagos a hacer. El pago de los equipos principales del proceso se llevará a cabo íntegramente durante los dos primeros años de vida de la planta (el año de construcción y el primer año de producción). La distribución de los pagos podría ser la siguiente:

\section{Tasa interna de rentabilidad (TIR)}

En este caso el valor obtenido para el TIR es del $20,1 \%$.

\section{Conclusiones}

El proyecto trató de desarrollar un estudio, tanto técnico como económico, sobre la viabilidad de la producción de biocombustibles (bioetanol en este caso) a partir de suero lácteo generado en queserías artesanales de la sierra del Perú.

Dada la pequeña dimensión del caudal de suero lácteo a tratar pronto se ve que la alternativa no debe pasar tan sólo por la obtención del biocombustible, sino que sería necesario un mayor aprovechamiento de la materia prima a fin de que la propuesta resultase atractiva en términos económicos. Así se llega de que el óptimo aprovechamiento del suero debe implicar también la separación y comercialización de la materia grasa presente en el mismo como de las proteínas.

A la vista de los resultados del análisis técnico del proceso, fue viable. Tanto la producción de etanol como la obtención del concentrado proteico y graso son procesos que ya han sido llevados a cabo a nivel de laboratorio e industrial, la tecnología

Tabla 8: Posible distribución de pagos de la inversión inicial

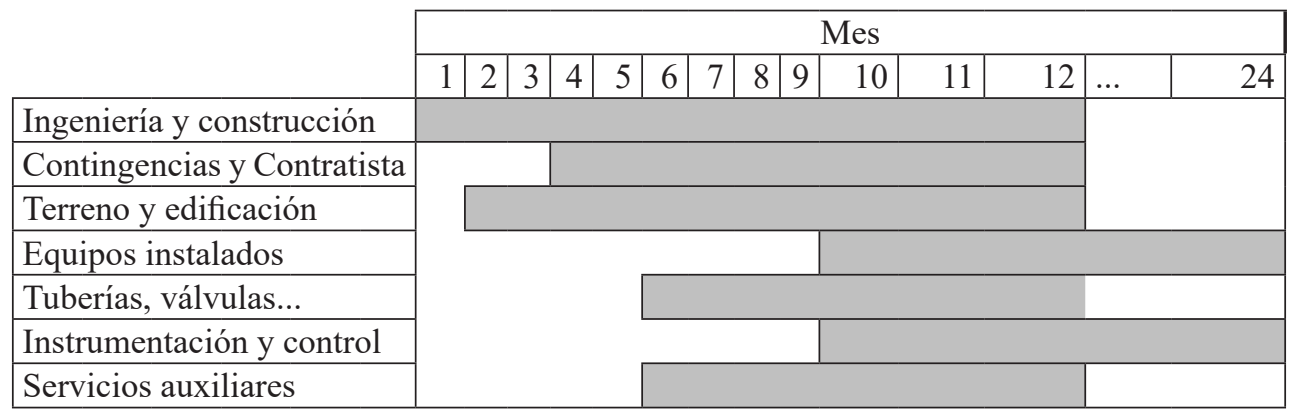

En los cálculos se observaron que en el séptimo año de vida de la planta (sexto año de producción) se ha recuperado toda la inversión inicial en la misma. Al finalizar el periodo de vida útil se llegaría a un flujo de caja positivo aproximado de 10,4 millones de soles. necesaria para ello está lo suficientemente desarrollada y la adquisición de los equipos adecuados no debería suponer ningún inconveniente. Debe ser indispensable la previa integración del conjunto de todas las operaciones involucradas en el proceso a nivel de planta piloto a fin de comprobar que no hay fallos en el proceso, ya que no se tiene constancia de la existencia de ninguna 
planta que las reúna a todas ellas.

La evaluación económica realizada muestra resultados aparentemente favorables, por lo que el proyecto podría ser objeto de estudios económico-financieros más detallados a fin de corroborar estos indicios.

\section{Literatura citada}

García, P.A.; Rico, J.L.; Fdz-Polanco, F. 1991. Anaerobic treatment of cheese whey in a two-phase uasb reactor. Environmental technology 12(4): 355-362.

Greer, D. 2008. The whey to renewable energy. BioCycle 49(2): 40

Guimarães, P.M.; Teixeira, J.A.; Domingues, L. 2010. Fermentation of lactose to bio-ethanol by yeasts as part of integrated solutions for the valorisation of cheese whey. Biotechnology advances 28(3): 375-384.

Hsu, C.K.; Kolbe, E. 1996. The market potential of whey protein concentrate as a functional ingredient in surimi seafoods. Journal of dairy science 79(12): 2146-2151.

Jelen, P. 2011. Utilization and Products. Whey Processing. In: Encyclopedia of Diary Sciences, 2nd edn. Fuquay JF, editor. Academic Press - An Imprint of Elsevier 4: 731-738.

Kühl, S.; Fahlbusch, M.; Ermann, M.; Brümmer, B.; Schulze-Ehlers, B. 2016. Der markt für milch und milcherzeugnisse im jahr 2015. German Journal of Agricultural Economics 65(6702019-659): 18-39.

Maiorella, B.L.; Castillo, F.J. 1984. Ethanol, biomass, and enzyme production for whey waste abatement. Process biochemistry 19(4): 157-161.

Onwulata, C.I.; Huth, P.J. 2008. Whey processing, functionality and health benefits. Ames: Blackwell Publishing $400 \mathrm{pp}$.

Parrondo, J.; Garcia, L.A.; Diaz, M. 2000. Production of an alcoholic beverage by fermentation of whey permeate with Kluyveromyces fragilis I: primary metabolism. Journal of the Institute of Brewing 106(6): 367-375.

Pérez-Bermúdez, I.; Garrido-Carralero, N.
2011. Aspectos a tener en cuenta en la operación de un sistema de deshidratación de alcohol por tamices moleculares. ICIDCA. Sobre los Derivados de la Caña de Azúcar 45(1): 57-63.

Peters, M.S.; Timmerhaus, K.D.; West, R.E.; Timmerhaus, K.; West, R. 1968. Plant design and economics for chemical engineers (Vol. 4). New York: McGraw-Hill.

Prazeres, A.R.; Carvalho, F.; Rivas, J. 2012. Cheese whey management: A review. Journal of environmental management 110: 48-68.

Rosenberger, A.; Kaul, H.P.; Senn, T.; Aufhammer, W. 2001. Improving the energy balance of bioethanol production from winter cereals: the effect of crop production intensity. Applied Energy 68(1): 51-67.

Siso, M.I.G. 1996. The biotechnological utilization of cheese whey: A review. Bioresource Technology 57: 1-11.

Tan, K.T.; Lee, K.T.; Mohamed, A.R. 2008. Role of energy policy in renewable energy accomplishment: the case of second-generation bioethanol. Energy policy 36(9): 3360-3365.

Walstra, P.; Wouters, J.T.M.; Geurts, T.J. 2006. Dairy science and technology (2nd ed.). New York: CRC Press. 768 pp. 